\title{
ESTUDO DA INFLUÊNCIA DA CIRCULAÇÃO LOCAL EM EVENTOS DE PRECIPITAÇÃO EXTREMA NO VALE DO ITAJAÍ (SC)
}

\author{
Ruy de Sá Prudêncio ${ }^{(a)}$, Maria Laura Guimarães Rodrigues ${ }^{(b)}$, Jonas Teixeira Nery ${ }^{(c)}$, Elaine \\ Pissi ${ }^{(d)}$
}

(a) IG, UNICAMP, ruysap@ige.unicamp.br

(b) Ciram, EPAGRI, mlauragr@gmail.com

(c) IG, UNICAMP, jonas@ ourinhos.unesp.br

(d) Faed, UDESC, elainepizzi@gmail.com

\section{Eixo: Climatologia em diferentes níveis escalares: mudanças e variabilidades}

\begin{abstract}
Resumo
Estudos de chuva extrema no litoral catarinense identificaram a presença de um anticiclone no Atlântico Sul, com ausência de frentes frias. Nesse trabalho, analisa-se a influência dos ventos locais na precipitação intensa em Itajaí (SC), para esse padrão atmosférico. Foram utilizados dados de precipitação diária acima de $50 \mathrm{~mm}$ e ventos horários locais, de 1998 a 2009 e reanálises do NCEP. Nos 14 casos selecionados, obsevou-se vento sinótico em superfície associado a um anticiclone na costa Sul do Brasil e um cavado no litoral Sudeste do país. A maior parte da chuva diária concentrouse em 12 horas. Para totais acima de $100 \mathrm{~mm}$, nos horários de chuva mais intensa ocorreu uma intensificação na velocidade do vento local. $\mathrm{O}$ caso de vento sudoeste-noroeste, à noite, indica uma possível influência da circulação de vale montanha, enquanto os casos de vento de sudeste/leste no período diurno indicam uma possível influência da circulação de brisa marítima.
\end{abstract}

Palavras chave: eventos extremos, circulação sinótica, circulação térmica, chuva.

\section{Introdução}

O estado de Santa Catarina é afetado por variados tipos de sistemas e perturbações atmosféricas que ocasionam eventos extremos de chuva. Isso propicia a ocorrência de desastres naturais, como enxurradas, inundações e deslizamentos de encosta, que causam muitos danos, desde prejuízos na área econômica até perdas humanas. Herrmann (2001) selecionou eventos de desastres naturais que ocorreram em Santa Catarina de janeiro de 1980 a julho de 2000. De acordo com a autora, no período estudado ocorreram 1.215 enchentes, 322 enxurradas e 116 deslizamentos de encosta no estado, sendo causados por eventos de precipitação extrema. Diante disso, é importante conhecer as principais características no padrão da circulação atmosférica associada a esses desastres, tanto em escala sinótica como em escala regional.

Severo (1994) identificou cinco grupos de sistemas atmosféricos sinóticos que produzem chuvas intensas no Vale do Itajaí, em Santa Catarina. Em um desses grupos, foi encontrado o predomínio de um sistema de alta pressão no Atlântico Sul, próximo da costa Sul do Brasil, favorecendo um fluxo de umidade em 
baixos níveis direcionado do oceano para a região do Vale do Itajaí. Rodrigues and Ynoue (2016) encontraram este mesmo padrão atmosférico para eventos de chuva extrema na região da Grande Florianópolis,com ausência de frentes frias, evidenciando a importância de um fluxo de umidade em baixos níveis, direcionado do oceano para o litoral (entre leste e nordeste) algumas horas antes do início da precipitação. Na região da Serra do Mar em São Paulo, Blanco (1999) observou que a intensificação orográfica da precipitação ocorre com elevados índices de umidade relativa na superfície e vento de sudeste, em associação à circulação gerada por um sistema de alta pressão no Atlântico Sul.

Essa circulação de ventos em superfície proveniente do oceano, mencionada pelos autores, encontra as barreiras da região formada pela Serra do Mar, que se estende desde o Rio de Janeiro até o Norte de Santa Catarina, com altitudes entre 800 m e 1.800 m (De Almeida e Carneiro, 1998). Além disso, a presença da serra contribui no processo de formação da brisa de vale-montanha, com grande influência no vento local em municípios situados entre as áreas de encosta e oceano adjacente.

Nesse trabalho, será analisada a influência dos ventos locais nos casos de precipitação intensa na região de Itajaí, para um padrão atmosférico sinótico associado à presença de um anticiclone no Atlântico Sul, com ausência de frentes frias. A região de estudo está localizada na bacia do Itajaí, porção nordeste do estado de Santa Catarina, Região Sul do Brasil (Figura 1). A bacia tem por delimitação, ao norte, o Planalto Norte e a Serra de Jaraguá; a oeste, a escarpa da Serra Geral, até alcançar a Serra da Boa Vista; e em direção ao oceano, a Serra de Tijucas. O estudo de Prudêncio (2002) indica a influência da topografia na região de Itajaí, conferindo um incremento da circulação de vale-montanha no processo da circulação local, e favorecendo ventos entre oeste e sudoeste no período noturno.

\section{Material e Métodos}

Para a realização desse trabalho, foram utilizados dados das estações meteorológicas (convencional e automática) localizadas em Itajaí $\left(26^{\circ} 57^{\prime} 01^{\prime}\right.$ 'S; 48 $\left.45^{\prime} 41^{\prime \prime} \mathrm{W}\right)$, Vale do Itajaí, conforme Figura 1, e pertencente à rede de monitoramento da EPAGRI (Empresa de Pesquisa Agropecuária e Extensão Rural de Santa Catarina). Foram obtidos dados de precipitação, direção e velocidade do vento, para os anos de 1998 a 2009. Posteriormente, foram separados os casos de precipitação diária maior que 50 mm, e, desses, selecionados aqueles com predomínio de vento sinótico do quadrante entre sudeste e nordest, com ausência de frente fria. Severo (1994) selecionou casos de precipitação intensa em Santa Catarina, utilizando uma média de precipitação diária acima de $50 \mathrm{~mm}$. 


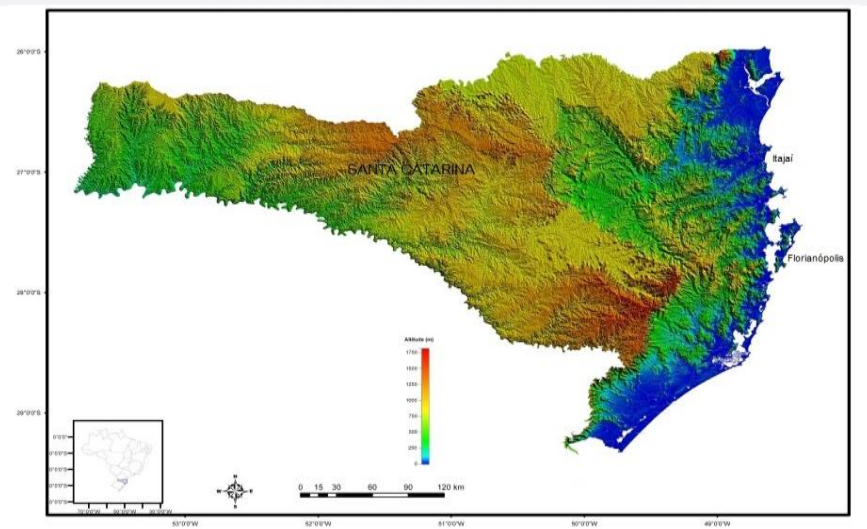

Figura 1 - Localização da área de estudo. Litoral de Santa Catarina e região de Itajaí.

Para análise dos casos, foram utilizadas imagens do satélite meteorológico (Goes/Noaa) e reanálises do NCEP (National Centers for Environmental Prediction), dos campos de Pressão ao Nível do Mar (PNMM) e ventos em superfície; geopotencial e ventos no nível isobárico de $500 \mathrm{hPa}$ (aproximadamente 5.500 metros de altura). Esses campos foram elaborados a cada 6 horas, nos horários de 00 UTC, 06 UTC, 12 UTC e 18 UTC, para o dia do registro de precipitação acima de $50 \mathrm{~mm}$ e dia anterior.

Também foram obtidos, na Defesa Civil de Santa Catarina, dados referentes à ocorrência de desastres naturais na região de estudo, para os eventos selecionados.

\section{Resultados e Discussão}

No total, foram 66 casos de precipitação diária acima de $50 \mathrm{~mm}$ na estação de Itajaí, sendo 14 casos (Tabela 1) com registro de vento sinótico entre sudeste e nordeste e sem passagem frontal, conforme diagnóstico dos campos de Pressão ao Nível do Mar (PNMM) e ventos em superfície. Em todos os casos a chuva persistiu por mais de um dia, porém com totais diários inferiores a $50 \mathrm{~mm}$. Somente os casos de 10 a 13 pertencem a um mesmo episódio, caracterizado por uma mesma condição sinótica e com chuva diária acima de $50 \mathrm{~mm}$ em 4 dias consecutivos, entre 21 e 24/11/2008.

Tabela I - Eventos selecionados de chuva extrema (acima de 50mm) em Itajaí/SC.

\begin{tabular}{cccc}
\hline Casos & Data & $\begin{array}{c}\text { Precipitação } \\
\text { 24h (mm)* }\end{array}$ & $\begin{array}{c}\text { Precipitação } \\
\mathbf{1 5 h , ~ 2 1 h , ~ 0 9 h} \\
(\mathbf{m m}) * *\end{array}$ \\
\hline $\mathbf{0 1}$ & $4 / 1 / 1998$ & 147 & $2,7-2,1-142$ \\
$\mathbf{0 2}$ & $7 / 11 / 2003$ & 231 & $15,9-26,5189$ \\
$\mathbf{0 3}$ & $23 / 1 / 2004$ & 82,2 & $0,0-0,0-82,2$ \\
$\mathbf{0 4}$ & $12 / 4 / 2004$ & 59,9 & $42,7-17,0-0,2$ \\
$\mathbf{0 5}$ & $19 / 9 / 2005$ & 63,8 & $4,8-43,1-15,9$ \\
$\mathbf{0 6}$ & $23 / 9 / 2005$ & 88,5 & $1,1-39,7-47,7$ \\
$\mathbf{0 7}$ & $2 / 10 / 2006$ & 71 & $2,5-31,6-36,9$ \\
\hline
\end{tabular}




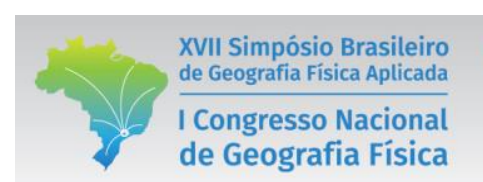
OS DESAFIOS DA GEOGRAFIA FÍSICA NA FRONTEIRA DO CONHECIMENTO Instituto de Geociências - Unicamp
Campinas - SP
28 de Junho à 02 de Julho de 2017

de Geografia Física

\begin{tabular}{cccc}
\hline $\mathbf{0 8}$ & $31 / 1 / 2008$ & 60 & $2,4-2,4-55,2$ \\
$\mathbf{0 9}$ & $21 / 4 / 2008$ & 101 & $49,0-42,5-9,3$ \\
$\mathbf{1 0}$ & $21 / 11 / 2008$ & 105 & $0,8-70,1-33,6$ \\
$\mathbf{1 1}$ & $22 / 11 / 2008$ & 92 & $40,9-15,036,1$ \\
$\mathbf{1 2}$ & $23 / 11 / 2008$ & 191 & $45,0-37,0-$ \\
& & & 108,5 \\
$\mathbf{1 3}$ & $24 / 11 / 2008$ & 70,9 & $39,0-23,0-8,9$ \\
$\mathbf{1 4}$ & $23 / 4 / 2009$ & 58,8 & $6,1-44,9-7,8$ \\
\hline
\end{tabular}

** $15 \mathrm{~h}$ (entre $9 \mathrm{~h}$ e $15 \mathrm{~h}$ ); $21 \mathrm{~h}$ (entre $15 \mathrm{~h}$ e $21 \mathrm{~h}$ ); $9 \mathrm{~h}$ (entre $21 \mathrm{~h}$ do dia anterior e $9 \mathrm{~h}$ do dia)

Em todos os casos da Tabela 1 foi identificada a presença de um anticiclone (sistema de alta pressão) no Atlântico Sul, na altura entre as latitudes de $40^{\circ} \mathrm{S}-35^{\circ} \mathrm{S}$, observado na Figura 2 . O centro do anticiclone no oceano pode estar mais afastado da costa da América do Sul (Figura 2a, do dia 4/1/1998), ou mais próximo (Figura 2b, do dia 21/04/2008 e Figura 2c, do dia 21/11/2008).

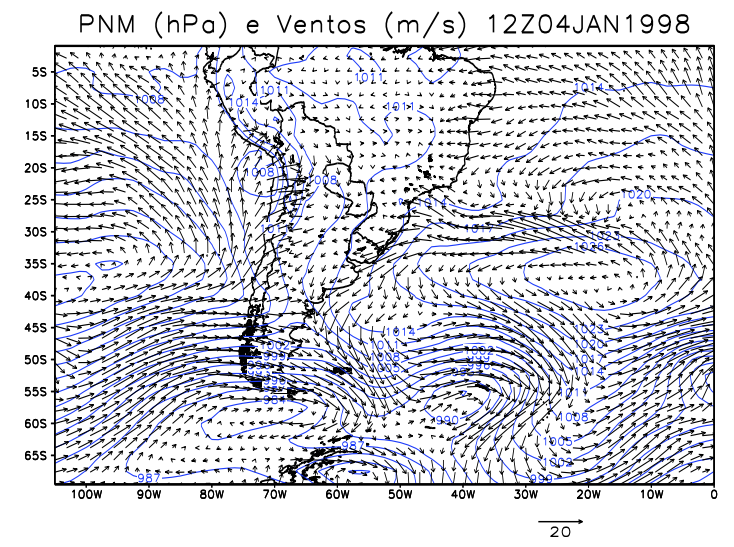

Figura 2a - Circulação de ventos em superfície no dia 04/01/1998 (caso 1).

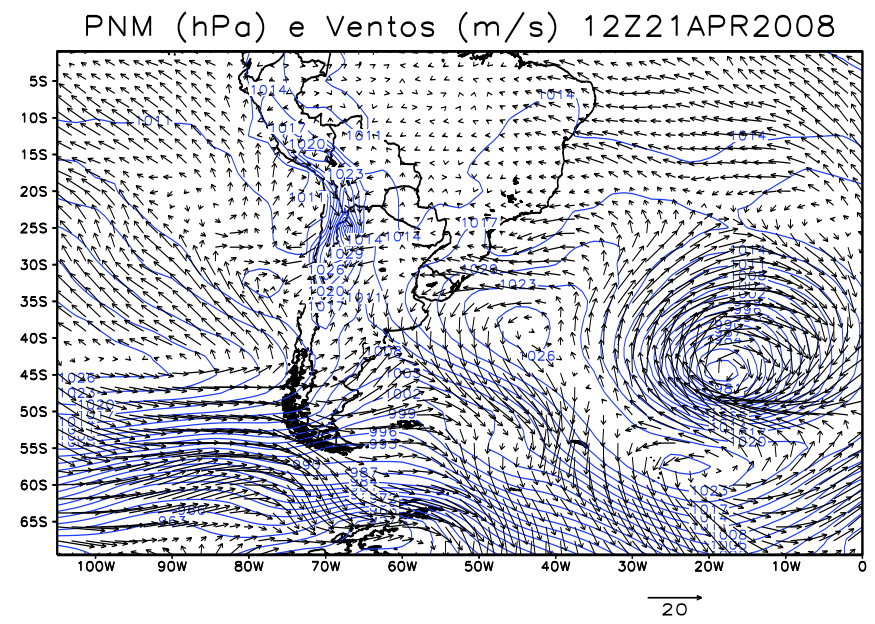

Figura 2b - Circulação de ventos em superfície no dia 21/04/2008 (caso 9). 


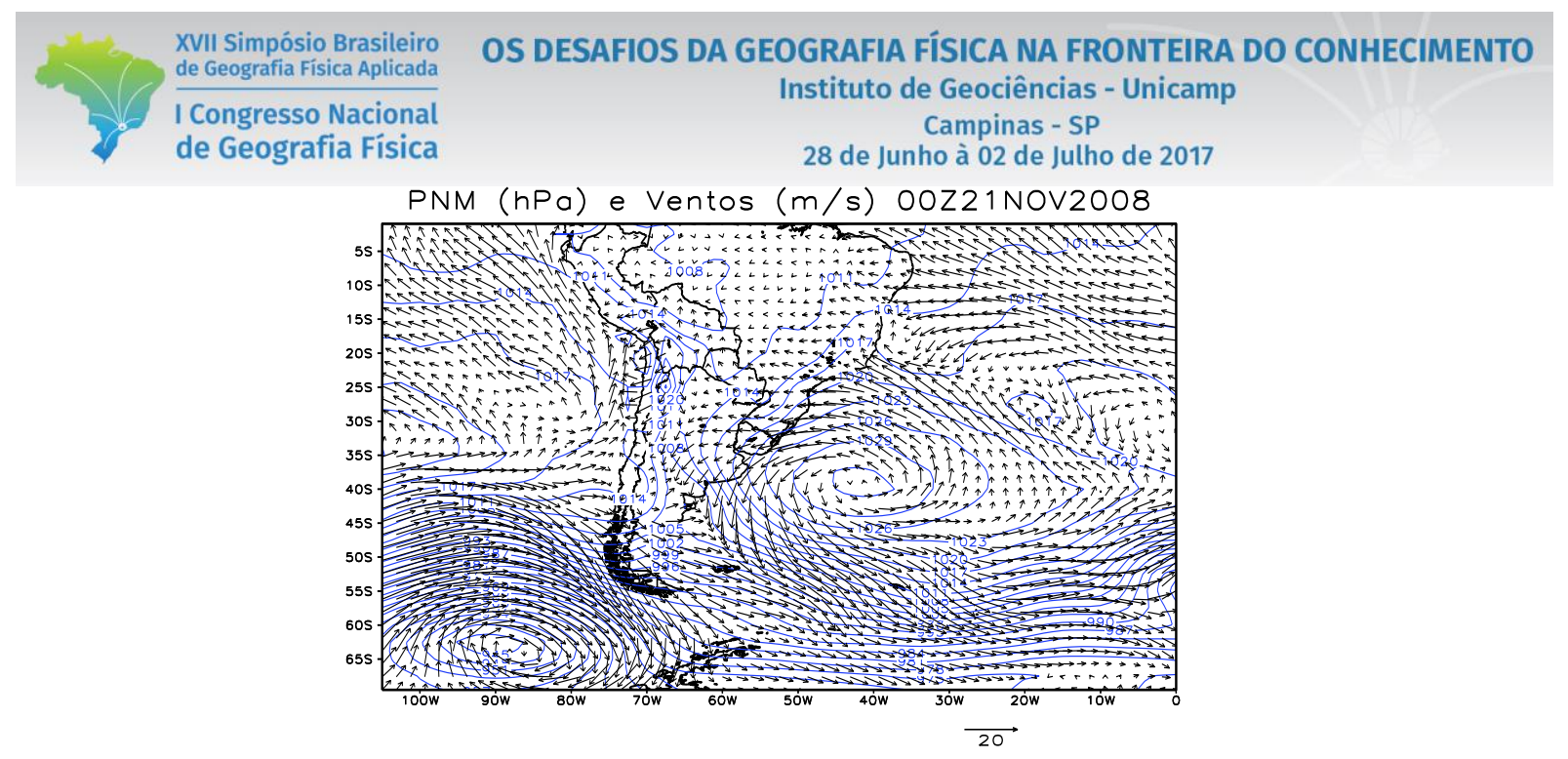

Figura 2c - Circulação de ventos em superfície no dia 21/11/2008 (caso 10).

Na maior parte dos casos, foi observada a presença de um cavado no litoral Sudeste do Brasil (Figura 2a e 2b). Entre o cavado e a alta pressão no oceano, forma-se uma circulação aproximadamente de leste no litoral catarinense. O caso 8, de 31/01/2008, foi estudado por Rodrigues e Ynoue (2016), para chuva intensa na Grande Florianópolis. Nos eventos de chuva mais intensa, acima de 100mm/dia (Tabela 1), foi identificado um ciclone em médios níveis $(500 \mathrm{hPa})$ no Sul do Brasil, como nos casos analisados por Rodrigues e Ynoue (2016) para a Grande Florianópolis.

Em geral, a maior parte da chuva diária concentrou-se em 12 horas. Em metade dos casos, no período da noite, enquanto na outra metade, entre a manhã e tarde (Tabela 1). Nos casos de maiores totais em 24 horas, de $147 \mathrm{~mm}, 231 \mathrm{~mm}$ e $191 \mathrm{~mm}$ (casos 1, 2, 12), a chuva concentrou-se no período da noite, entre $21 \mathrm{~h}$ do dia anterior às $9 \mathrm{~h}$ do dia, com respectivamente $142 \mathrm{~mm}, 189 \mathrm{~mm}$ e 108,5mm em 12 horas.

Entre os 14 casos da Tabela 1, cinco apresentaram totais diários acima de 100mm: 1, 2, 9, 10 e 12 . Para esses, foram analisados os dados horários da direção e velocidade do vento da estação meteorológica local (disponível para os casos 2, 9 e 12). Nos horários de chuva mais intensa, a velocidade do vento também intensificou-se, ficando acima de 20km/h (Figura 3a, 3b e 3c), com direção de vento sudoeste-noroeste (caso 2), sul-sudeste (caso 9) ou sudeste-nordeste (caso 12). 


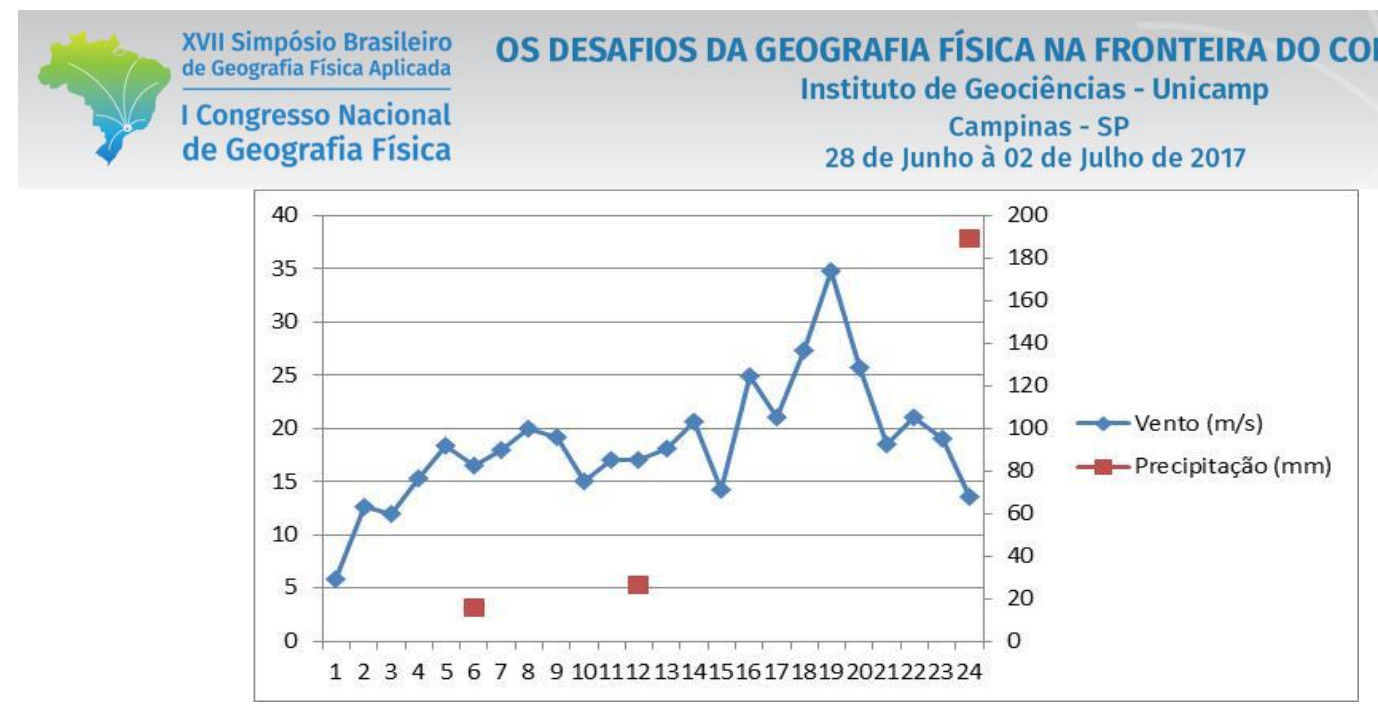

Figura 3a - Precipitação e velocidade do vento no dia 07/11/2003 (caso 2).

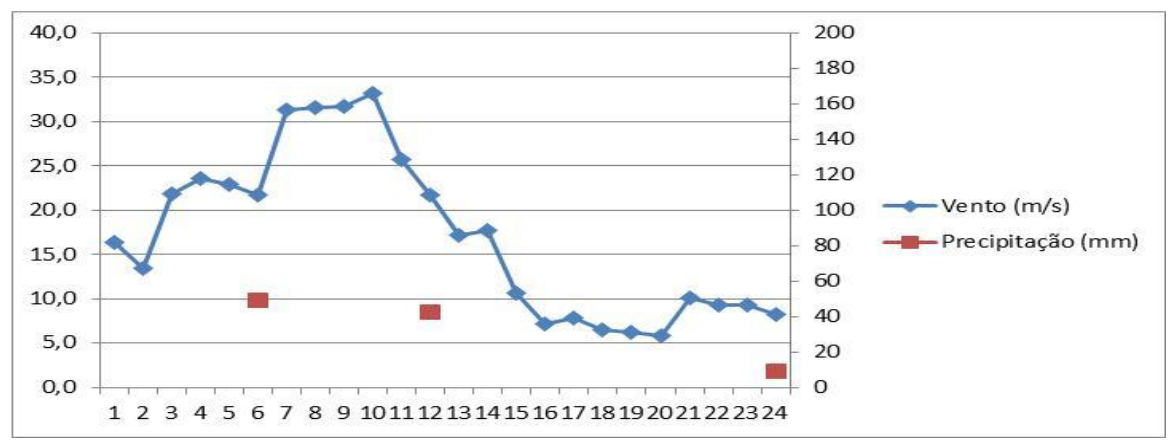

Figura 3b - Precipitação e velocidade do vento no dia 21/04/2008 (caso 9).

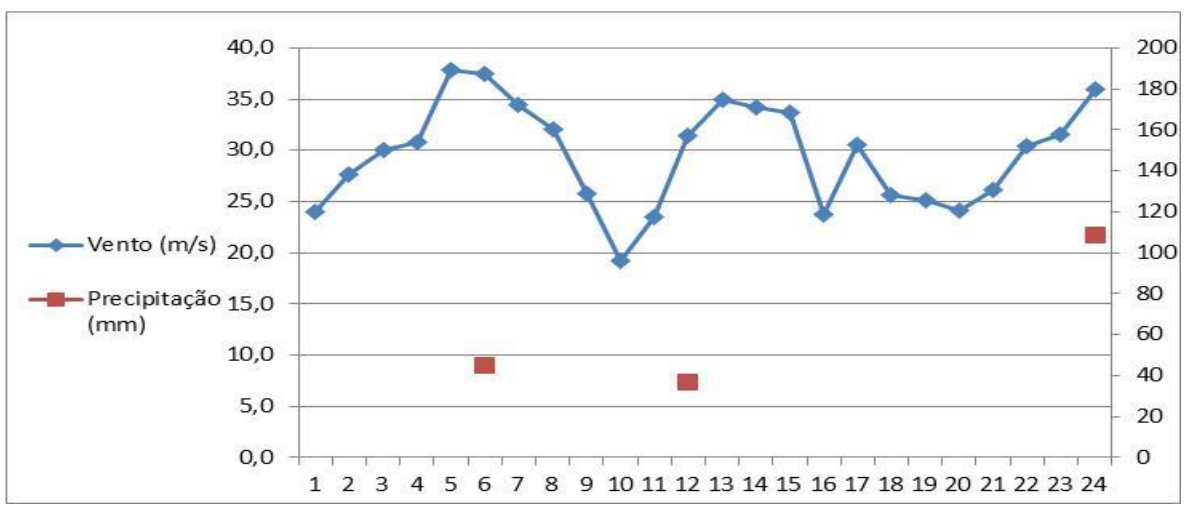

Figura 3c - Precipitação e velocidade do vento no dia 23/11/2008 (caso 12).

No caso 2, que registrou o maior total de precipitação em 12 horas (189mm), o vento local de sudoestenoroeste (oposto ao vento sinótico), no período noturno, indica uma possível influência da circulação de vale-montanha, identificada com forte sinal na região de Itajaí no estudo de Prudêncio (2002), entre 23h e 08h. Nos demais, o vento local esteve associado ao sistema atmosférico predominante e a chuva mais intensa ocorreu tanto no período diurno (caso 9, com sul-sudeste) como no período diurno e noturno (caso 


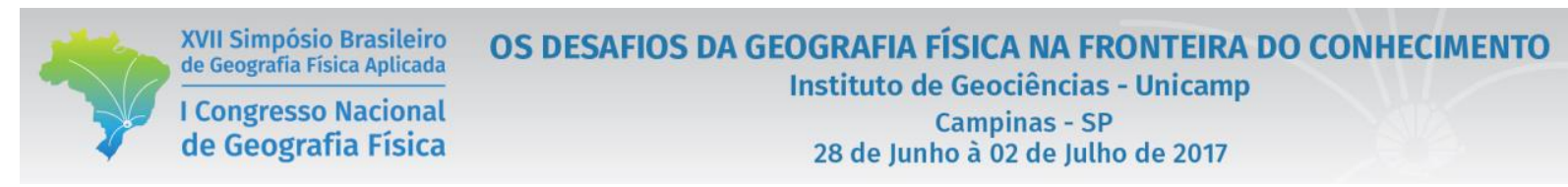

12, com sudeste-nordeste). Nesses dois últimos, a velocidade do vento ultrapassou os $30 \mathrm{~km} / \mathrm{h}$, especialmente durante o dia e para uma direção de vento sudeste-leste, indicando uma possível influência da circulação de brisa marítima intensificando o vento sinótico na rgeião.

Dos 14 dias de chuva extrema, apresentados nesse estudo (Tabela 1), em 8 dias foram registrados desastres naturais na região de Itajaí. Os desastres foram todos do tipo inundação brusca, conforme classificados pela Defesa Civil de Santa Catarina. Esses registros ocorreram nos eventos de número 1, 2, 4, 8 e nos 4 dias do evento 10 . No evento 8 , foram registrados 16 casos de inundação brusca. No evento 10, foram 6 casos no dia 21/11; 10 no dia 22/11; 11 no dia 23/11 e 27 no dia 24/11. Conforme Smith (1979), em eventos de chuva intensificada pela orografia são esperadas inundações bruscas.

\section{Conclusões}

Entre os casos de precipitação diária acima de 50 milímetros na região de Itajaí, em cerca de 20\% (14 casos) foram obsevados ventos sinóticos em superfície aproximadamente de leste no litoral catarinense. Essa circulação está associada à presença de um anticiclone na costa Sul do Brasil e de um cavado no litoral Sudeste do país, sem passagem frontal. Esses resultados estão de acordo com estudos de outros eventos de chuva intensa no litoral de Santa Catarina.

Em geral, a maior parte da chuva diária concentrou-se em 12 horas, no período diurno ou noturno. Nos cinco casos com totais em 24 horas acima de 100 mm, identificou-se um ciclone em médios níveis da atmosfera e chuva concentrada no período da noite. Nesses eventos, nos horários de chuva mais intensa, observou-se uma intensificação na velocidade do vento local.

No caso 2, o vento local de sudoeste-noroeste, oposto ao vento sinótico, no período noturno, indica uma possível influência da circulação de vale-montanha, contribuindo para uma convergência da circulação local. Nos casos 9 e 12, o intenso e persistente vento local de sudeste-leste, no período diurno, indica uma possível influência da circulação de brisa marítima intensificando o vento sinótico.

Em metade mais da metade dos caos houve registro de inundação brusca, conforme classificados pela Defesa Civil de Santa Catarina, o que pode ser esperado em casos de chuva intensificada pela orografia.

\section{Bibliografia}

BLANCO, C. M. R. Processos de intensificação orográfica da precipitação na Serra do Mar em São Paulo. Dissertação de Mestrado em Meteorologia, USP, 1999.

DE ALMEIDA, F. F. M., \& CARNEIRO, C. D. R. Origem e evolução da Serra do Mar. Revista Brasileira de Geociências, 28, p. 135-150, 1998. 
HERRMANN, M. L. DE P. Levantamento dos desastres naturais causados pelas adversidades climáticas no Estado de Santa Catarina, período 1980 a 2000. Florianópolis: IOESC, 2001, 90 p.

PRUDÊNCIO, R. S. Estudo do sistema de circulação de brisas no litoral de Santa Catarina. Monografia de Especialização em Meteorologia, UFPel, 2002.

RODRIGUES, M. L. G., \& YNOUE, R. Y. Mesoscale and synoptic environment in three orographicallyenhanced rain events on the coast of Santa Catarina (Brazil). Weather and Forecasting, Boston, v.31, n. 5, p. 1529-1546, 2016.

SEVERO, D. L. Estudo de casos de chuvas intensas no estado de Santa Catarina. Dissertação de Mestrado em Meteorologia, INPE, 1994. 